\title{
Mapeamento dos veículos de comunicação da cidade de Imperatriz-
} MA

\author{
Letícia Holanda de Sousa' \\ Marcos Fábio Belo Matos²
}

\section{Resumo}

Este artigo se propõe a traçar um mapeamento dos veículos de comunicação: rádio, televisão, jornal impresso, revista e internet (blogs, sites e portais) de Imperatriz, segunda maior cidade do Maranhão, localizada na região sudoeste do estado. A pesquisa foi realizada entre outubro de 2016 e abril de 2018. O objetivo principal deste trabalho é elaborar um panorama dos veículos e programas jornalísticos locais. A metodologia utilizada foi quantitativo-descritiva, com aporte de pesquisa bibliográfica para descrever o cenário histórico e atual da comunicação de Imperatriz. Como resultado, pôde-se constatar que Imperatriz dispõe de dois grandes jornais impressos, "O Progresso", veículo mais tradicional, e o jornal "Correio". A cidade conta ainda com 09 revistas, 10 emissoras de rádio, 08 veículos de televisão e 40 páginas na plataforma online (blogs, sites e portais). Este levantamento tem a importância de fazer uma radiografia dos veículos e programas do município, podendo ser aproveitado para estudos futuros na área da comunicação de Imperatriz, da região e do estado.

Palavras-chave: Mapeamento. Jornalismo. Imprensa. Imperatriz-MA.

\section{Abstract}

This article has the purpose to elaborate a mapping of the vehicles of communication: radio, television, newspaper, magazines and Internet (blogs, websites and Internet portals) of Imperatriz, the second biggest city of Maranhão, located in Southwest region of the state. The research was accomplished among October 2016 and April 2018. The main goal of this work is to elaborate an outlook of the vehicles and local jornalistic programs. The methodology used was quantitative-descriptive, with collaboration of bibliographic research to detail the historical and current scenario of communication in Imperatriz. As a result, It may be concluded that Imperatriz hamunics 02 important newspaper companies, "O

\footnotetext{
1 Graduada em Comunicação Social/Jornalismo pela Universidade Federal do Maranhão (UFMA), Campus de Imperatriz-MA. E-mail: letyhollanda@gmail.com.

2 Pós-doutor em Comunicação pela Universidade do Vale do Rio dos Sinos (UNISINOS-São Leopoldo), doutor em Linguística e Língua Portuguesa pela Universidade Estadual Paulista (UNESP-Araraquara), professor do Curso de Comunicação Social - Jornalismo da Universidade Federal do Maranhão (UFMA), Campus de Imperatriz-MA. Integrante do Neec e do Lidime. E-mail: marcosfmatos@gmail.com.
}

Revista Pauta Geral-Estudos em Jornalismo, Ponta Grossa, vol. 6, n. 1, p. 131-147, Jan/Jun, 2019. 
Progresso", the most traditional vehicle, and the newspaper called "Correio". The city still constitutes 09 magazines, 10 radio stations, 08 television vehicles and 40 online pages (blogs, websites and Internet portals). This research has the importance to make a radiography of the media vehicles and programs of the city, supporting to be used to future studies in the communication area of Imperatriz, of the region and of the state.

Keywords: Mapping. Jornalism. Press. Imperatriz-MA.

\section{Introdução}

Este trabalho é fruto de uma pesquisa maior intitulada: "A implantação da Fábrica Suzano de Papel e Celulose no jornal "O Progresso" em Imperatriz (MA): uma análise de conteúdo", realizada na Universidade Federal do Maranhão (UFMA).

Para a sua realização, foram mapeados os veículos de comunicação da cidade de Imperatriz: rádio, televisão, jornal impresso, revista e internet (blogs, sites e portais), além dos respectivos programas jornalísticos desses veículos.

A pesquisa foi efetivada entre outubro de 2016 e abril de 2018, com a finalidade de levantar um panorama dos meios de comunicação do município. O objetivo é identificar o que permanece e o que muda no cenário comunicacional da cidade, dos primórdios da imprensa local, até os dias atuais.

Como percurso metodológico, foi realizado, em primeiro lugar, um levantamento de referências, dentre as quais foram analisados textos (entre livros e artigos) sobre a história da imprensa e o cenário comunicacional de Imperatriz. A discussão teórica traz as considerações de Assunção e Pinheiro (2012), que abordam a chegada dos jornais impressos e da televisão em Imperatriz; Bueno e Batalha (2017), que traçam um perfil da internet na cidade; Silva et al (2017), que analisam a trajetória das revistas em Imperatriz; e Brito e Maciel (2012), que descrevem o percurso do rádio na região.

Como aporte metodológico também se utiliza a pesquisa quantitativa, que, segundo Gehlen (2014), trata-se de uma técnica para obtenção de dados da pesquisa por meio da análise percentual. No que se refere ao método quantitativo, Gerhardt e Silveira (2009) o definem como um processo que avalia objetivamente e quantifica a coleta e análise dos dados, ofertando, numa pesquisa, resultados numéricos.

No segundo momento, foi elaborado o mapeamento a partir das pesquisas nos sistemas de busca na plataforma digital e por meio de contato com profissionais das emissoras da cidade. A etapa do mapeamento foi desenvolvida em três fases: coletas de Jan/Jun, 2019. 
dados, mapeamento e montagem das tabelas. O critério de escolha dos veículos e programas se restringiu ao fato de os mesmos apresentarem conteúdos de caráter jornalístico. A partir disso, foi traçada a cartografia comunicacional local, que inclui: rádio, televisão, revista, jornal impresso e internet (blogs, sites e portais).

\section{O cenário do jornalismo impresso em Imperatriz}

O surgimento da imprensa em Imperatriz ocorreu com o aparecimento dos jornais no formato impresso. Na década de 1930, a cidade, localizada no sudoeste do Maranhão, presencia a chegada do jornalismo no município, por meio da fundação do jornal "O Alicate", pelo então escrivão Antônio José Marinho, nascido em Grajaú-MA (ASSUNÇÃO; PINHEIRO, 2012).

O período de 1932 a 1964, como classifica Assunção (2011), representa a primeira fase do jornalismo em Imperatriz. A autora ainda destaca que esse é o momento da circulação dos primeiros jornais da cidade: "O Alicate" (1932), "A Luz" (1936), "O Astro" (1949) e o "Correio do Tocantins" (1964). Uma característica desse período de nascimento da imprensa local é o fato de que o número de impressos segue um movimento de estagnação, quando foram encontrados poucos jornais em circulação. Neste cenário do jornalismo na cidade, Assunção e Pinheiro (2012) explicam que, somente no ano de 1970, houve uma expansão da mídia local, com o nascimento dos primeiros veículos de rádio, televisão, novos impressos e as principais revistas.

Ao vislumbrar o nascimento dos veículos na década de 1970, observa-se a chamada "segunda fase da imprensa escrita de Imperatriz". É o momento em que se verifica a multiplicação dos periódicos na cidade. Conforme Assunção e Pinheiro (2012), no ano de 1970, registram-se seis títulos de jornais e, na década de 1980, houve um aumento no número de periódicos circulando em Imperatriz, com cerca de 49 títulos, classificados em religiosos, culturais, institucionais, de interesse geral, políticos, sindicais, de emissora de televisão, negócios, educação e estudantis.

É também nesta época que surge o jornal "O Progresso", o periódico mais tradicional da imprensa de Imperatriz, fundado no dia 03 de maio de 1970, pelo então empresário José Matos Vieira e o advogado e jornalista Jurivê Macedo. No início, o jornal apresentava quatro páginas, com circulação semanal e trazia informações sobre a identidade de Imperatriz (ASSUNÇÃO; PINHEIRO, 2012). O jornal "O Progresso" 
incorporava nas páginas o discurso sobre o desenvolvimento da região, o que pode ser verificado tanto pela escolha do seu próprio nome - O Progresso - quanto na sua memória fundadora, como se pode ver ressaltado neste trecho do primeiro editorial do jornal:

Chegamos até aqui que não é ainda a nossa meta. É nossa aspiração
fazer deste noticioso um instrumento a serviço da coletividade de que
somos parte. E que através de "O PROGRESSO" possa a voz de
Imperatriz fazer-se sentir em outros rincões, levando até eles a
demonstração da pujança desta terra querida que dia a dia desperta para
novos rumos e novos empreendimentos, estuante de vida, marco de
transição entre o marasmo que ficou sufocado pelas máquinas que
rasgaram a Belém-Brasília e os horizontes que se descortinaram ante os
olhos de uma geração que surge (O PROGRESSO, "NOSSA
CAMINHADA", 03.05.1970).

Atualmente, o jornal "O Progresso", conforme Novakoski (2016), é o único impresso de circulação diária, com tiragem de aproximadamente quatro mil exemplares por dia. A impressão é feita em offset, formato tabloide francês, com capa colorida e 16 páginas em preto e branco, divididas em 9 editorias: Política, Cidade, Regional, Polícia, Esportes, Social, Geral, Tocantins e, aos domingos, Cultura, produzida pela Academia Imperatrizense de Letras.

Na década de 1970, Imperatriz vivencia ainda um período de extensas mudanças econômicas, sociais e culturais. É neste cenário que se verifica o impulso para surgimento das primeiras revistas da cidade. Em 15 de outubro de 1997, é publicada a revista "Momento", com as primeiras versões, sendo produzida por Aureliano Neto, Jurivê Macedo, Osvaldo Alencar e Hiroshi Bogéa. A revista circulava quinzenalmente e contava com 22 páginas, divididas pelas editorias de política, entrevistas, editorial, cultura e esporte, além de evidenciar um perfil alternativo (SILVA et al, 2017).

Um ano após o aparecimento da primeira revista, conforme Silva et al (2017), em agosto de 1998, surge o segundo título na mídia imperatrizense, chamada de revista "Motivação", pertencente à Associação Comercial e Industrial de Imperatriz (ACII). Organizada em 21 páginas, a revista era voltada apenas aos sócios da ACIl e tratava exclusivamente de assuntos econômicos e empresariais da cidade e região.

No ano de 1979, nasce a terceira revista da imprensa de Imperatriz, chamada "Juçara Clube". Administrada pela Sociedade Imperatriz de Desportos, o veículo possuía oito páginas e tinha uma circulação mensal, destinada aos sócios daquela entidade.

Revista Pauta Geral-Estudos em Jornalismo, Ponta Grossa, vol. 6, n. 1, p. 131-147, Jan/Jun, 2019. 
Em relação ao processo de produção, as primeiras revistas se assemelhavam ao formato praticado nos veículos impressos. Mas, na realidade da comunicação local, o “jornalismo de revista não se consolidou enquanto prática no município, já que os títulos da localidade dispõem de um teor mais de colunismo social, do que de jornalismo". (SILVA et al, 2017, p. 138)

Já na terceira fase da imprensa local, conforme Assunção (2011), entre os anos de 1990 e 2010, é registrada a etapa de consolidação da mídia escrita imperatrizense. Nesta época, os números de impressos cresceram, houve a transposição dos periódicos para plataforma digital e se verificou a contínua interferência dos jornais na área da política de Imperatriz.

Com o desenvolvimento da mídia, chega às mãos dos leitores outro periódico, que ganha espaço no jornalismo local, o jornal "Correio Popular". O impresso surge em outubro de 2009, nomeado como "Correio de Imperatriz", e, em seguida, no período de dois anos, muda o nome para "Correio Popular", lançando a primeira versão impressa, em março de 2011 (ALMEIDA et al, 2015). Com intuito de fazer um jornalismo diferenciado e popular, Maciel (2011) ressalta que o "Correio", no início, circulava semanalmente, no formato tabloide, com 12 páginas, trazendo a capa, contracapa e as páginas centrais coloridas.

Conforme Almeida et al (2015), em 23 dezembro de 2013, o jornal paralisa as atividades, devido às comemorações de final de ano, mas, logo depois, não retorna com a circulação, declarando, em março de 2014, o fim da circulação do "Correio Popular". A partir dessa ação, os leitores se depararam com a transposição definitiva do periódico para a internet.

Assim, ao realizar a pesquisa sobre o cenário da comunicação de Imperatriz, verifica-se que a cidade possui, atualmente, 02 grandes jornais, que permanecem em circulação diária: "O Progresso", mais tradicional, também na versão online; e o "Correio Popular", segundo mais lido na região, disponibilizado apenas em formato digital, com a inovação de chegar aos 40.000 leitores pelo aplicativo de conversas WhatsApp.

Já em relação ao jornalismo de revista, confere-se que o município possui 9 títulos em circulação: revistas "Linda Glamour", “Estrelas”, "Motivação", “Mega”, "Inovação", "Agora", "Interespaço", "Saber" e "Leia Mais". Compreende-se que nem todas as revistas possuem caráter totalmente informativo. Alguns títulos, como "Glamour", "Estrelas" e 
"Motivação", são revistas que trazem informações, mas prevalecem o entretenimento e o colunismo, principalmente no intuito de veicular notícias sobre a vida de empresários e pessoas de renome da cidade. Há também os títulos voltados para o jornalismo científico, ou seja, revistas que divulgam as atividades das universidades e as pesquisas científicas do município.

\section{O percurso do rádio em Imperatriz}

Somente na década de 1960 é que se verificam os primeiros registros com rádio em Imperatriz, impulsionado por Francisco Marques Ramos. Este eletrotécnico foi o responsável por colocar no ar a primeira emissora, a "Rádio Cipó", sendo clandestina e com mil watts de potência (BRITO; MACIEL, 2012). Outro idealizador, conforme Brito e Maciel (2012) registram, foi o eletrotécnico Raimundo Nogueira de Sousa Neto, que, na metade da década de 1960, instalou a "Rádio Mirim", outra emissora clandestina. Nesta época, os incentivadores entraram em parceria e aumentaram a estrutura da "Rádio Mirim" e, em 1966, a rádio foi vendida para Leôncio Pires Dourado, passando a se chamar "Rádio Imperatriz". Entretanto, por ser clandestina, a emissora foi fechada tempos depois.

Já no final da década de 1970, Imperatriz presencia a fundação da primeira emissora devidamente legalizada. Com o incentivo político do ministro de Minas e Energia, Edison Lobão e do senador Henrique de La Rocque, em 28 de outubro de 1975 instala-se na cidade a "Rádio Imperatriz Sociedade Limitada", tendo como responsável o empresário e radialista Moacyr Spósito Ribeiro, natural de São Paulo (BRITO; MACIEL, 2012)

A "Rádio Imperatriz" alcançava municípios da região do Maranhão, Pará e Tocantins. Na grade de programação da emissora, que funcionava de 5 horas da manhã à meia-noite, foram exibidos alguns programas, como: "A Fazenda do Corró", "Canta Brasil", "Domingo Feliz", "Faixa Nobre", "Musi Carta”, "Rancho do Compadre Paulo", "Rádio Festa", "Românticos do povo", "Sentinela Policial", "Sertão Alegre", "Sua Carta Vale Música”, entre outros (BRITO; MACIEL, 2012). Em relação aos programas de cunho jornalístico que circulavam na rádio, destaca-se como marco o "Jornal 890": "Geralmente os primeiros cinco minutos eram notícias internacionais e nacionais, o segundo bloco com notas regionais e a última parte era destinada às notícias policiais" (BRITO; MACIEL, 2012, p.09).

Revista Pauta Geral-Estudos em Jornalismo, Ponta Grossa, vol. 6, n. 1, p. 131-147, Jan/Jun, 2019. 
Outros programas jornalísticos que fizeram parte da emissora foram: o "Jornal dos Municípios", destinado a veicular conteúdos das prefeituras da Região Tocantina; o "Café da Manhã", programa voltado para assuntos políticos e sociais e o "Casos de polícia", apresentado por Paulo Negrão, trazendo boletins informativos (BRITO; MACIEL, 2012). A partir daí, disputando espaço na comunicação da cidade, a "Rádio Imperatriz" cumpria o papel de informar a população imperatrizense e de regiões circunvizinhas, com notícias direcionadas mais para área da política e polícia.

A "Rádio Imperatriz" ficou no ar cerca de 27 anos, veiculando notícias e entretenimento, e, em 2005, após a morte do proprietário, ela foi vendida para a Associação Cidade Esperança, com a programação voltada para o público evangélico (BRITO; MACIEL, 2012).

O jornalismo sempre esteve presente no percurso de implantação do rádio em Imperatriz. Dez anos depois da inauguração da pioneira e legalizada "Rádio Imperatriz", surge, em novembro de 1989, a primeira emissora de frequência modulada FM, a "Rádio Nativa", de propriedade do empresário e político Raimundo Cabeludo: "Além da primeira transmissão jornalística em FM, a rádio foi a primeira a retransmitir via satélite uma rede de rádios que contribuiu com várias parcerias entre elas a Rede Som Zoom Sat, de Fortaleza-CE" (FERNANDES et al, 2014, p. 09).

Criada para atender aos aspectos do jornalismo, Fernandes et al (2014) destacam que a rádio veiculava uma grade de programação totalmente voltada para as narrativas jornalísticas, como o primeiro programa jornalístico que ia ao ar das 06 às $07 \mathrm{~h}$ da manhã, além do programa do Connor Farias, Amaral Reis e Renilson Sousa. Alguns programas ganhavam o título dos próprios locutores que os conduziam.

A emissora contava com 17 programas, sendo 7 veiculados de segunda a sextafeira e 10 no sábado e domingo, conduzidos por: Arimateia Junior, Banana Locutor, Edy Soares, Leo Miller, Marcinha, Martielle, Neide Oliveira, Renald Café, Valdinês Lima. Fernandes et al (2014) registram ainda o programa "Rádio Alternativo", apresentado por Raimundo Cabeludo e de cunho jornalístico, que levava ao público notícias do campo político e policial da região.

O mapeamento do panorama comunicacional dos veículos radiofônicos demonstra que Imperatriz conta com 10 emissoras de rádio em funcionamento, sendo 7 emissoras comerciais. A maior delas é a "Rádio Mirante FM", localizada na frequência 95,1 MHz, 
com os programas: "Mano Santana", "Estopim", entre outros, com o estilo mais musical e a emissora "Mirante AM", localizada na frequência 830, com 12 programas, entre eles, o "Acorda Maranhão", "Mirante Esporte”, “Jornal do Maranhão” e "Abrindo o Verbo". As duas rádios são ligadas ao Sistema Mirante de Comunicação, afiliado da Rede Globo. A "Rádio Difusora Sul" é ligada ao Sistema Brasileiro de Televisão-SBT, localizada na frequência 105,1MHz e conta com os programas: "Ligação Direta", "Carlos Alberto" e "A Grande Jogada", com a característica de terem, além da música, a informação. A "Rádio Nativa", pertencente à "TV Nativa", está localizada na frequência 99,5 MHz, possui 17 programas, com destaque para o programa jornalístico "Rádio Alternativo". Outra emissora comercial da cidade é a "Rádio Terra FM", que fica localizada na frequência 100,3 MHz, com sete programas, entre eles, "Transito Livre", "Terra Online" e "Fim de Tarde", sempre acompanhados de música e boletins de notícias.

Imperatriz conta ainda com 02 rádios voltadas para o público evangélico, são elas: "Rádio Cidade AM", encontrada na frequência $570 \mathrm{kHz}$, com uma grade de programação evangélica, além dos boletins de informações e o programa "Jornais dos Jornais" e a "Rádio 102 FM", que veicula os programas "Giro Esportivo" e "Resenha Esportiva" e se encontra na frequência $102,7 \mathrm{MHz}$. Atualmente, a emissora não possui programas jornalísticos, somente boletins de notícias.

Já as rádios "Missão FM" e "Maranhão do Sul" são 02 emissoras comunitárias. A "Missão FM" fica localizada na frequência $106,3 \mathrm{MHz}$ e conta com os programas "Sociedade em Foco" e "Missão esportivo" e a "Maranhão do Sul", encontrada na frequência $87,9 \mathrm{MHz}$, possui os programas "Comunidade em Ação" e "Debate Comunitário".

Outra emissora catalogada é a "Rádio Caema", com característica de rádio- poste. $\mathrm{Na}$ grade de programação, a rádio veicula os programas "Estação Caema", "Mistura Musical" e "Jornal da Caema".

No que diz respeito ao panorama radiofônico da cidade, percebe-se que há uma audiência ainda considerada no espaço do rádio. Verifica-se que os programas de maiores audiências são aqueles que buscam uma proximidade com os ouvintes, como o programa do Arimateia Junior, na "Rádio Nativa" e "Mano Santana", na Rádio Mirante FM.

\section{O cenário da televisão local}

Revista Pauta Geral-Estudos em Jornalismo, Ponta Grossa, vol. 6, n. 1, p. 131-147, Jan/Jun, 2019. 
Em meados da década de 1970, Imperatriz ainda não detinha registro de uma emissora de televisão. Os primeiros ensaios com televisão na cidade foram realizados em outubro de 1967, conforme Frasão (2014), com a doação de um aparelho televisor e uma antena, o que permitiu que o eletrotécnico Francisco Ramos e Pedro Bala captassem pela primeira vez o sinal de televisão no município. Enquanto Pedro Bala subia e colocava a antena, Francisco Ramos sintonizava (FRASÃO, 2014). Assunção e Pinheiro (2012) explicam que o sinal era de uma televisão boliviana, que na época veiculava a morte do líder guerrilheiro Che Guevara.

Assunção e Pinheiro (2012) registram que, somente em 1975, a televisão é oficialmente homologada em Imperatriz, com os sinais simultâneos das TVs Tupi e Globo. Os equipamentos da TV foram comprados por Francisco Ramos e Raimundo Vieira, o Cabeludo, na cidade de Manaus AM. Frasão (2014) ressalta que a concessão do sinal da TV foi adquirida com o apoio do então senador maranhense José Sarney, em Brasília. A retransmissora de TV, localizada no canal 4, ficou sob o controle da prefeitura municipal, durante quatros anos.

Além do incentivo de Francisco Ramos, Frasão (2014) destaca a colaboração também de José Moreira e Osvaldo Nascimento, com a instalação e captação de diversos sinais de televisão na cidade. Três anos depois, Imperatriz presencia a chegada da segunda retransmissora de televisão, de propriedade do Francisco Ramos, que antes prestava serviço para a TV Imperatriz e se tornou responsável, junto com empresário Raimundo Cabeludo e o político Bayma Júnior, pela "TV Tropical", afiliada da Rede Bandeirantes, que hoje é a "TV CRC" - Chico do Rádio Comunicações (FRAZÃO, 2014).

Em 1981, conforme Frasão (2014), a cidade ganha o sinal do Sistema Brasileiro de Televisão (SBT), por meio da "TV Karajás", de propriedade de Francisco Ramos, Raimundo Cabeludo, J. Moreira e Osvaldo Nascimento. A "TV Karajás" originou a "TV Difusora Sul". Pinheiro e Santos (2017) explicam que a "TV Difusora" foi instalada no ano de 1991, com a razão social Rádio Curimã Ltda. Pinheiro e Santos (2017) revelam ainda que o veículo possuía outro nome de fantasia, chamada "TV Alvorada" e, somente em 1989, o Ministério da Comunicação liberou a concessão da televisão.

Em 1983, segundo Frasão (2014), é criada a "TV Curimã", retransmissora da Rede Manchete de Televisão, de propriedade do Raimundo Cabeludo, hoje Sistema Nativa de Comunicação. A autora revela ainda que, em 1984, surgiu a "TV Educativa", pertencente

Revista Pauta Geral-Estudos em Jornalismo, Ponta Grossa, vol. 6, n. 1, p. 131-147, Jan/Jun, 2019. 
ao governo municipal de José de Ribarmar Fiquene. Na grade de programação, a emissora veiculava assuntos voltados mais para a área da educação e cultura. "Extinta no final da década de 1980, ela foi responsável pelo lançamento de muitos profissionais no telejornalismo local" (FRAZÃO, 2014, p. 23).

Outro veículo a ser implantado na cidade foi a "TV Imperatriz". Frasão (2014) exemplifica que a emissora chega para atender aos aspectos da produção jornalística local, com notícias voltadas para o cenário social e econômico da época, como os conflitos agrários, violência urbana e a infraestrutura do município. No roteiro de programação, a televisão exibia os programas: "Bom Dia Local", que ia ao ar de segunda à sexta feira, das $7 \mathrm{~h} 30$ às $8 \mathrm{~h}$, o "Tocantins TV", às 12h25, o “Jornal Regional”, exibido a partir das $19 \mathrm{~h} 45 \mathrm{e}$, às 23h20, o "Boa Noite Tocantins" (FRASÃO, 2014).

No ano de 1990, conforme Frasão (2014), instalou-se a "TV Capital", de propriedade do empresário Conor Farias, afiliada à TV Record. Além da fundação da "TV Anajás", em 2003, veiculada à Rede Vida de Televisão.

De acordo com os dados obtidos da pesquisa, Imperatriz dispõe de 08 emissoras de televisão em funcionamento. O veículo de maior audiência é a "TV Mirante", localizada no canal 10, retransmissora da Rede Globo. Na grade de programação, a emissora conta com 03 programas jornalísticos: o jornal "JMTV $1^{\text {a }}$ edição", às 12 horas de segunda a sábado, com duração de 45 minutos; o "JMTV 2a edição", veiculado às 19 horas, de segunda a sábado e o "Globo Esporte", programa voltado para notícias de esporte de Imperatriz e da Região Tocantina, exibido às $12 \mathrm{~h} 45$, de segunda a sábado, com duração de 5 a 8 minutos. Esses jornais se direcionam a divulgar informações voltadas para política, saúde, educação, esporte, policial e comunidade.

Outra emissora de elevada audiência é a "TV Difusora Sul", encontrada no canal 7 , filiada ao Sistema Brasileiro de Televisão (SBT), com destaque para os 04 programas jornalísticos: o "Bandeira 2", exibido de segunda a sexta-feira, das 6 às 7 horas, com o perfil mais de jornalismo policial; o jornal "Bom Dia Maranhão do Sul”, veiculado das 7 às 8 horas, de segunda a sexta-feira; o "Jornal da Difusora", apresentado das 12 às 12h45, de segunda a sexta-feira e o programa "Difusora Repórter". A televisão busca uma aproximação entre o veículo e a comunidade local e traz um jornalismo mais popular, levando até os telespectadores da cidade e regiões vizinhas notícias da área política, educação, saúde, esporte, policial, comunidade e bairros.

Revista Pauta Geral-Estudos em Jornalismo, Ponta Grossa, vol. 6, n. 1, p. 131-147, Jan/Jun, 2019. 
A cidade conta também com a "TV Capital", localizada no canal 5, afiliada da Rede TV. A emissora veicula programas locais, políticos, esportivos, informativos e comerciais, além do telejornal "Imperatriz 24h", exibido de segunda a sexta-feira.

A "TV CRC Band" é uma retransmissora da Rede Bandeirante, sintonizada no canal 4, com a cobertura de assuntos direcionados para o esporte, política, ciência, tecnologia, educação e saúde, atendendo à região tocantina. Assim, o veículo traz na grade de programação 06 programas, são eles: "Maranhão Legal", apresentado de segunda a sexta-feira, às $12 \mathrm{~h} 30$, com meia hora de duração; o "Você na TV", voltado para a comunidade local, exibido às 13 horas, com duração de 30 minutos; o "Imperatriz Agora" e o "Espaço do Alberto Sousa", veiculados de segunda a sexta-feira, às $13 \mathrm{~h} 35$, com notícias da cidade, além do "Notícia em Foco", que vai ao ar às 18h50, de segunda a sexta-feira e o programa "Fidélis Uchoa na TV".

Registra-se ainda a "TV Nativa", afiliada da Rede Record, sintonizada no canal 13, com os 05 programas jornalísticos: "Imperatriz Acontece", veiculado às 12 horas, de segunda a sexta-feira; "Balanço Geral", apresentado de segunda a sexta-feira, às 6 horas; jornal "Cidade Alerta Maranhão", exibido às 19:30h, de segunda a sexta-feira, além do "Café da Manhã", apresentado de segunda a sexta-feira, às 07:15h e o "Ponto de Vista", aos sábados, às 12 horas.

Já a "TV Tocantins" é uma emissora considerada universitária de Imperatriz, ligada ao grupo Facimp ${ }^{3}$, afiliada à Rede CNT e encontrada no canal 21, com 10 programas, sendo 09 exibidos de segunda a sexta-feira, com destaque para: "Enfoque Regional", das 07 às 8 horas; "Repórter Cidadão", das 11 às 12 horas; "Jornal dos Municípios", das 12 às 13 horas; "Focalizando", das 13 às 14 horas; "Imperatriz Agora", das 18 às 19 horas e "Conexão Cidade", das 20 às 20h30. Além do programa "Debate Esportivo", veiculado no sábado, às 10 horas.

No cenário da comunicação de Imperatriz, mapeiam-se ainda 02 emissoras de televisão, ligadas ao público religioso, são elas: "TV Anajás", localizada no canal 16, retransmissora da Rede Vida, voltada para o público católico e dirigida pela Diocese de Imperatriz, com 02 programas: o "Jornal da Diocese", exibido todos os sábados, às 12 horas e 18 horas, com reprise no domingo, às 9 horas e o "Repórter Nos Bairros" veiculado de segunda a sexta, às $12 \mathrm{~h} 30$ e às 15 horas, com notícias sobre as atividades

${ }_{3}$ Grupo que administra uma faculdade particular da cidade.

Revista Pauta Geral-Estudos em Jornalismo, Ponta Grossa, vol. 6, n. 1, p. 131-147, Jan/Jun, 2019. 
da igreja católica e do munícipio. Além da "TV Cidade Esperança", sintonizada no canal 14, pertencente à igreja evangélica e administrada pela Assembleia de Deus em Imperatriz, veiculando os programas "Conversa Franca", exibido às 12 horas, de caráter entrevista e o jornal "Cidade Esperança", às 12h40, de segunda a sexta-feira.

Em relação ao mapeamento da televisão, o que chama atenção é o crescimento do número de programas jornalísticos destinados a noticiar informações de Imperatriz e região. Percebe-se que, na trajetória histórica da TV, na medida em que as emissoras foram se estruturando, com equipamentos e profissionais, verifica-se um desenvolvimento da comunicação televisiva do município.

\section{A midiosfera: portais, sites, blogs}

Somente na década de 1990, notam-se as primeiras experiências da mídia de internet em Imperatriz. Bueno e Batalha (2017) exemplificam que, em meados de 1990, instala-se no espaço da web o pioneiro webjornal do município, o site do jornal impresso "O Progresso" (www.oprogresso.com). Encarregada de hospedar a página do jornal impresso, conforme Bueno e Batalha (2017), a empresa Júpiter Informática é a provedora de internet mais antiga em funcionamento da cidade. Além de manter o conteúdo do webjornal, entre 1998 a 2000, a empresa administrava um site próprio, com o objetivo de divulgar informações do município, sendo também precursora na imprensa online local (BUENO, BATALHA, 2017).

Bueno e Batalha (2017) registram ainda que, em 1990, outros veículos de comunicação criaram espaços de divulgação na rede, como foi o caso do site da rádio "Terra FM" (www.fmterra.com.br), a primeira página virtual de uma rádio de Imperatriz. A concepção de uma página para rádio visava a impulsionar a audiência, atendendo às solicitações dos ouvintes de outras regiões, além da utilização do site na veiculação de informações da cidade. Na década de 1990, Bueno e Batalha (2017) consideram que o número de páginas na web, para os assuntos jornalísticos, foi pequeno, somente na década de 2000 que se verifica o crescimento dos veículos que aderiram à internet:

Sites de conteúdo especializado, a maioria deles voltado para o público religioso; páginas institucionais, que começaram a produzir notícias; outros veículos tradicionais que migraram para a web; além do mercado de entretenimento, com sites de eventos e agendas marcaram o período e a história da imprensa virtual nas terras à beira do rio Tocantins (BUENO; BATALHA, 2017, p. 211).

Revista Pauta Geral-Estudos em Jornalismo, Ponta Grossa, vol. 6, n. 1, p. 131-147, Jan/Jun, 2019. 
Já em setembro de 2002, idealizado por Kenedy Rocha Ribeiro e Jackson dos Santos, membros da União Municipal dos Estudantes Secundárias-UMES, entram no ar


voltados para o modelo de página típico de entretenimento, com coberturas de eventos, no formato de notícias e fotografias (BUENO; BATALHA, 2017).

As autoras registram que, nos anos 2000, surgiram alguns webjornais de referências nesse formato de jornalismo em Imperatriz. Em 2010, surge o site "Imperatriz Notícias" (www.imperatriznotícias.com.br), com produção feita por acadêmicos do curso de Comunicação Social/Jornalismo, da Universidade Federal do Maranhão (UFMA), e dirigido por professores da graduação. A página é voltada para produção jornalística da região Tocantina. Já em 2012, ligado à empresa de comunicação e publicidade Canal Comunicação, entra no ar o site "Do Minuto" (www.dominuto.com), o primeiro site comercial de caráter específico para web, veiculando conteúdo jornalístico, saindo em 2013 do ar por dificuldades financeiras.

Bueno e Batalha (2017) registram ainda surgimento do site "Imirante Imperatriz" (www.imirante.com/imperatriz), voltado para jornalismo diário online e vinculado à emissora do grupo Mirante, ligada à Rede Globo. Em 2010, nasce a página online do jornal impresso "Correio Popular", deixando de circular a versão impressa em 2013.

Em relação aos blogs de Imperatriz, Bueno e Fonseca (2013) constatam que o blog da Diocese de Imperatriz é a página mais antiga em funcionamento, ligado à igreja católica, com o domínio desde 26 de dezembro de 2013. "A blogosfera de Imperatriz apresenta uma gama diversificada de temáticas trabalhadas: acontecimentos locais, política, esporte, religião e educação" (BUENO; FONSECA, 2013, p.17).

No cenário jornalístico da internet, o mapeamento revela que Imperatriz conta com 40 páginas na plataforma digital, subdivididas entre portais, sites e blogs, sendo 4 portais de notícia, entre eles: "Portal do Guigui" (www.portaldoguigui.com.br/), "Maranhão do Sul" (www.portalsuldomaranhao.com.br), "Imperanews" (www.imperanews.com.br) e o portal "Maranhão Notícias" (maranhaonoticias.com/portal).

Já em relação aos websites, foram mapeadas 09 páginas de site em Imperatriz, são elas: "Imirante/Imperatriz" (imirante.com/imperatriz); "Imperatriz Notícias" (www.imperatriznoticias.com.br); "G1 Globo Imperatriz" (g1.globo.com/ma/maranhao/cidade/imperatriz); "Prefeitura Municipal de Imperatriz"

Revista Pauta Geral-Estudos em Jornalismo, Ponta Grossa, vol. 6, n. 1, p. 131-147, Jan/Jun, 2019. 
(www.imperatriz.ma.gov.br); jornal "O Progresso" (www.oprogressonet.com); jornal "Correio Popular" (www.correiopopularitz.com.br); "Rádio FM Terra" (www.fmterra.com.br); "MA10" (www.ma10.com.br/maranhao/imperatriz) e o site "André Imprensa" (www.andreimprensa.com.br).

No panorama da mídia na web, destaca-se o crescimento do número de blogs no município. Bueno e Fonseca (2017) revelam o predomínio de weblogs de caráter jornalístico, mas voltados para a própria imagem do blogueiro. "Um aspecto curioso e que corrobora esta afirmação é que a maioria dos blogs recebe o nome do blogueiro" (BUENO, FONSECA, 2017, p. 12). A partir do mapeamento dos blogs feito por Bueno e Fonseca (2013), foram atualizadas as informações em relação aos blogs jornalísticos ativos em Imperatriz, como mostra a tabela 1:

Tabela 1: Blogs mapeados em Imperatriz

\begin{tabular}{|c|c|}
\hline $\begin{array}{l}\text { Blog do } \quad \text { Wilson } \\
\text { (blogwilsonleite.blogspot.com.br) }\end{array}$ & $\begin{array}{l}\text { Blog Paulo } \\
\text { (www.paulonegrao.com.br) }\end{array}$ \\
\hline $\begin{array}{lll}\text { Blog } & \text { do } & \text { Carlos } \\
\text { (carlosleen.blogspot.com.br) }\end{array}$ & $\begin{array}{l}\text { Blog do } \\
\text { (www.blogdofontinelle.com.br) }\end{array}$ \\
\hline $\begin{array}{lcc}\text { Blog } & \text { do } & \text { Élson } \\
\text { (porelsonaraujo.blogspot.com.br) }\end{array}$ & $\begin{array}{lll}\text { Blog do } & \text { Rui } & \text { Porão } \\
\text { (blogdoporao.com.br) } & & \end{array}$ \\
\hline $\begin{array}{lcc}\begin{array}{l}\text { Blog do } \\
\text { (willianmarinho.blogspot.com.br) }\end{array} & \text { Marinho } \\
\end{array}$ & $\begin{array}{lll}\begin{array}{l}\text { Blog } \\
\text { (vilsonsantos.blogspot.com.br) }\end{array} & \text { Sa } \\
\end{array}$ \\
\hline $\begin{array}{l}\text { Direto } \quad \text { da } \\
\text { (diretodaaldeia.blogspot.com.br) }\end{array}$ & $\begin{array}{l}\text { Blog do Prof. Jairo Nascimento } \\
\text { (professorjaironascimento.blogspot.com } \\
\text {.br) }\end{array}$ \\
\hline $\begin{array}{l}\text { Blog do } \quad \text { Marcelo } \\
\text { (blogmarcelolira.blogspot.com.br) }\end{array}$ & $\begin{array}{l}\text { Blog Imperatriz } \\
\text { (semusimperatriz.blogspot.com.br) }\end{array}$ \\
\hline $\begin{array}{l}\text { Blog Asmoimp/Jesnem } \\
\text { (asmoimp.blogspot.com.br) }\end{array}$ & $\begin{array}{lll}\text { Blog do Adalberto } & \text { Franklin } \\
\text { (adalbertofranklin.por.com.br) } & \\
\end{array}$ \\
\hline $\begin{array}{ll}\text { Blog } & \text { Carlos } \\
\text { (prensaitz.blogspot.com.br) }\end{array}$ & $\begin{array}{l}\text { Blog da } \\
\text { (www.blogdakellyitz.com.br) }\end{array}$ \\
\hline $\begin{array}{l}\text { Blog da Diocese de } \\
\text { (dioceseitz.blogspot.com.br) }\end{array}$ & $\begin{array}{l}\text { Blog do Gil } \\
\text { (www.gilcarvalho.net) }\end{array}$ \\
\hline $\begin{array}{l}\text { Blog do Chico Duvalle/Portal de Notícias } \\
\text { de } \\
\text { (chicoduvalle.blogspot.com.br) }\end{array}$ & $\begin{array}{l}\text { Blog Só falo a } \\
\text { (www.sofaloaverdade.net) }\end{array}$ \\
\hline $\begin{array}{l}\text { Blog Notícia da } \\
\text { (noticiadafoto.blogspot.com) }\end{array}$ & $\begin{array}{l}\text { Blog Informativo } \\
\text { (informativoaca.blogspot.com.br) }\end{array}$ \\
\hline 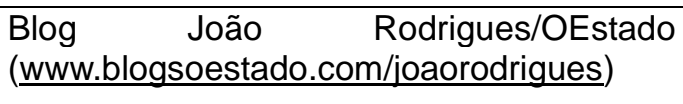 & $\begin{array}{l}\text { Blog do Josué Moura } \\
\text { (josuemoura.blogspot.con }\end{array}$ \\
\hline oto & (a \\
\hline
\end{tabular}

Revista Pauta Geral-Estudos em Jornalismo, Ponta Grossa, vol. 6, n. 1, p. 131-147, Jan/Jun, 2019. 
Blog do André Gomes

(andreimprensa.blogspot.com.br)

Fonte: Autores (2018)

Em relação aos blogs, a cidade dispõe de 27 páginas na web, com notícias principalmente na área da política e policial. Os weblogs "Notícia da Foto" e "Blog da Kelly" são os mais atualizados, com publicações de textos e fotos diariamente, além de destacar a publicidade como um dos meios de sobrevivência dos blogs. Percebe-se ainda que, dos 27 blogs de caráter jornalístico mapeados, 21 páginas recebem o nome dos administradores dos weblogs, mostrando o interesse dos blogueiros na autopromoção da imagem.

\section{Considerações finais}

O objetivo deste trabalho foi mapear o cenário atual da comunicação: rádio, televisão, jornal impresso, revista e internet (blogs, sites e portais) de Imperatriz, levando em consideração o material catalogado, no intuito de ser útil para estudos da comunicação local, regional e estadual. O mapeamento permite identificar o que permaneceu e mudou no universo da imprensa local. Com o levantamento, verifica-se que a comunicação do munícipio tem bastante força nas diversas plataformas, no jornalismo impresso, televisivo, radiofônico e na internet.

Valendo-se da catalogação dos veículos de comunicação, destaca-se o grande crescimento do setor da mídia digital, principalmente na área dos blogs, que reforça a autopromoção dos blogueiros na cidade.

Verifica-se, ao mesmo tempo, o decrescimento e a estagnação da mídia impressa, com predomínio apenas do tradicional jornal "O Progresso" e o "Correio Popular", este último sendo impresso apenas em ocasiões especiais e divulgando as suas edições regulares no WhatsApp.

Quanto ao jornalismo de rádio, constata-se um aumento dos veículos radiofônicos e programas jornalísticos na FMs e a queda das rádios de frequência AM.

No mapeamento das emissoras de TV, confere-se que na cidade há uma grande quantidade de veículos de televisão e programas locais de informação, tendo em vista a elevada audiência que se tem no espaço televisivo.

Revista Pauta Geral-Estudos em Jornalismo, Ponta Grossa, vol. 6, n. 1, p. 131-147, Jan/Jun, 2019. 
A maior constatação que se pôde fazer, com este levantamento, é que a midiosfera Imperatrizense continua acolhendo os mais diferentes dispositivos de mídia, mas mudando a importância e o alcance dos mesmos.

\section{Referências}

ALMEIDA, Domingos A. et al. Uma análise circunstancial do fim do Jornal Correio Popular de Imperatriz - MA. XVII CONGRESSO DE CIÊNCIAS DA COMUNICAÇÃO NA REGIÃO NORDESTE, 02 a 04 de julho de 2015. Anais.

ASSUNÇÃO, Thays Silva. Imprensa em Imperatriz - MA: uma proposta de periodização dos jornais impressos (1932 -2010). Trabalho de Conclusão de Curso (Graduação em Comunicação Social-Habilitação em Jornalismo) - Universidade Federal do Maranhão. Imperatriz, 2011.

ASSUNÇÃO, Thays Silva; PINHEIRO, Roseane Arcanjo. Jornalismo em Imperatriz - MA: os jornais impressos em tempo de mudança (1970-1989). In: Revista Brasileira De História Da Mídia, v.1, n.2, julho-dez. 2012.

BRITO, Nayane Cristina Rodrigues; MACIEL, Alexandre Zarate. Começou o jornal na rádio Imperatriz. II ENCONTRO NORTE-NORDESTE DE HISTÓRIA DA MÍDIA. Universidade Federal do Piauí, 20 e 21 de junho de 2012. Anais.

BUENO, Thaísa; BATALHA, Sara. Plugado na rede: levantamento apresenta os primórdios da mídia de Imperatriz na internet. In: BRITO, N.; REIS, R.; PINHEIRO, R.; ASSUNÇÃO, T. (orgs.). Jornalismo, mídia e sociedade: as experiências na região Tocantina. Imperatriz: EDUFMA, 2017.

BUENO, Thaisa; FONSECA, Jordana. Blogando das barracas do Rio Tocantins: uma proposta de mapeamento da blogosfera imperatrizense. 4 SIMPÓSIO DE CIBERJORNALISMO. Universidade Federal de Mato Grosso do Sul, 28 a 30 de agosto de 2013. Anais.

FERNANDES, Brenda et al. Buscando Alternativa: rádio Nativa FM. III ENCONTRO NORDESTE DE HISTÓRIA DA MÍDIA. Universidade Federal do Maranhão, 08 e 09 de maio de 2014. Anais.

FRASÃO, Geovana Carvalho. Newsmaking na Mira: um estudo comparativo entre a produção noticiosa do Jornal do Maranhão (JMTV) $1^{1^{a}}$ e $2^{\underline{a}}$ edições. Trabalho de Conclusão de Curso (Graduação em Comunicação Social-Habilitação em Jornalismo) Universidade Federal do Maranhão. Imperatriz, 2014.

GEHLEN, Marco Antonio. Amostragem e inferência nas pesquisas em jornalismo. XV CONGRESSO DE CIENCIAS DA COMUNICAÇÃO NA REGIÃO SUL/INTERCOM. 08 a 10 de maio de 2014. Palhoça, SC. Anais. 
GERHARDT, Tatiana Engel; SILVEIRA, Denise Tolfo (org). Métodos de pesquisa. Porto Alegre: Editora da UFRGS, 2009.

MACIEL, A. Z. Aqui Imperatriz!: perfis de pessoas comuns no Jornal Correio Popular. In: MATOS, Marcos Fábio Belo; Gehlen, Marco Antônio. (Org.). Comunicação, Jornalismo e Fronteiras Acadêmicas. São Luís (MA): Edufma, 2011.

NOVAKOSKI, Rhaysa Carvalho. O Desenho de uma Trajetória: design editorial nos jornais diários de Imperatriz (MA) de 1974 a 2013. Trabalho de Conclusão de Curso (Graduação em Comunicação Social-Habilitação em Jornalismo) - Universidade Federal do Maranhão. Imperatriz, 2016.

O PROGRESSO. Ano 1, N.1, 03.05.1970. Disponível em:

http://www.oprogressonet.com/edicao/preview/1. Acesso em 06.05.2018.

PINHEIRO, Roseane Arcanjo; SANTOS, Paula de Társsia. TV Difusora Sul: as práticas jornalísticas na década de 1990. In: BRITO, N.; REIS, R.; PINHEIRO, R.; ASSUNÇÃO, T. (orgs.). Jornalismo, mídia e sociedade: as experiências na região Tocantina. Imperatriz: Edufma, 2017.

SILVA, Irisvânia; ALVARENGA, Lorrane; PEREIRA, Margaret; ASSUNÇÃO, Thays. Apontamentos sobre as primeiras revistas de Imperatriz-MA. In: BRITO, N.; REIS, R.; PINHEIRO, R.; ASSUNÇÃO, T. (orgs.). Jornalismo, mídia e sociedade: as experiências na região Tocantina. Imperatriz: Edufma, 2017.

Recebido em: 24/03/2019.

Publicado em: 23/07/2019.

Revista Pauta Geral-Estudos em Jornalismo, Ponta Grossa, vol. 6, n. 1, p. 131-147, Jan/Jun, 2019. 